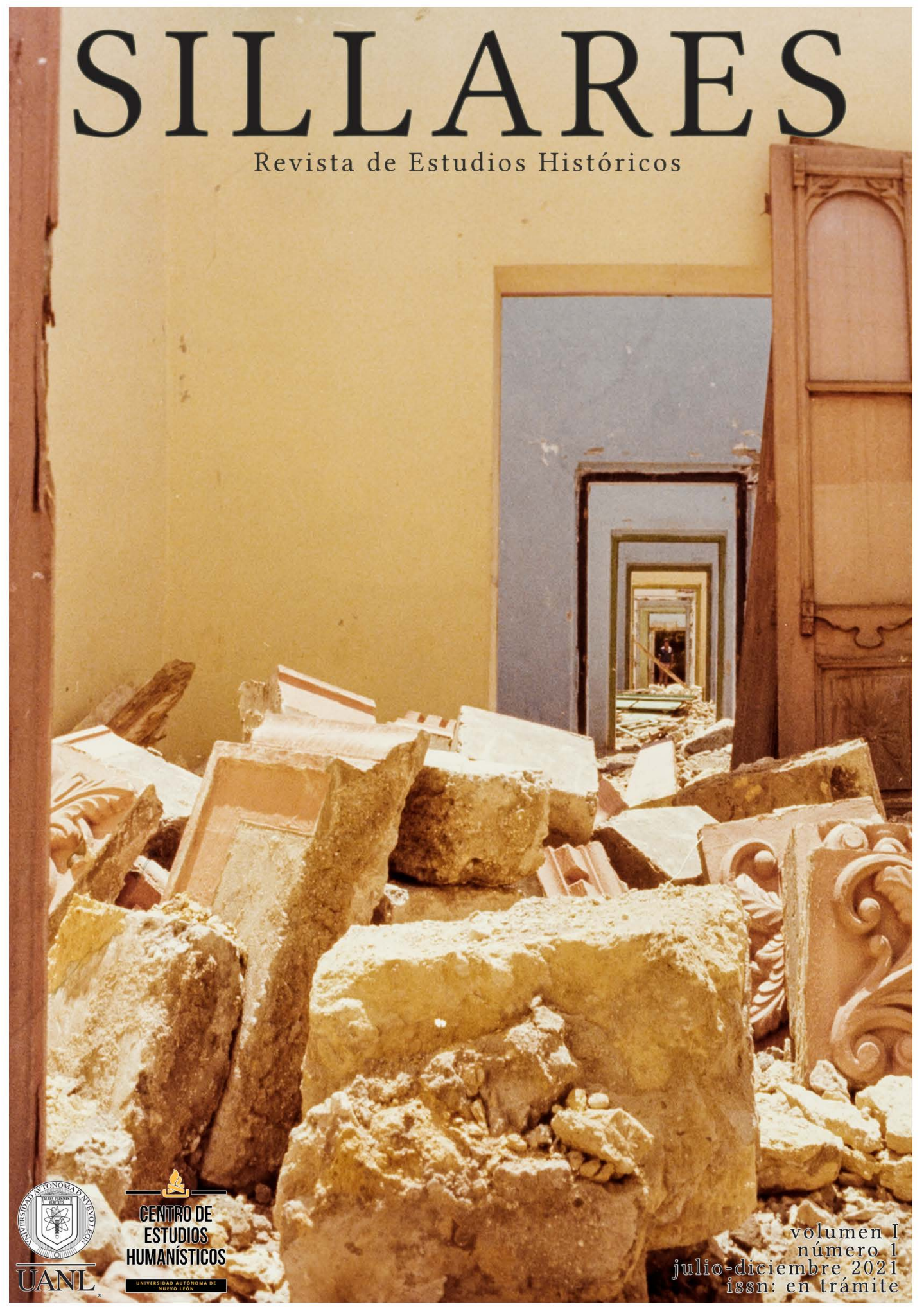


Rogelio G. Garza Rivera

Rector

Santos Guzmán López

Secretario General

Celso José Garza Acuña

Secretario de Extensión y Cultura

Humberto Salazar Herrera

Director de Historia y Humanidades

César Morado Macías

Titular del Centro de Estudios Humanísticos

José Eugenio Lazo Freymann

Director

Copyright: C 2021. Atribución-NoComercial-SinDerivadas 4.0 Internacional (CC BY-NC-ND 4.0).

ISSN en trámite

Sillares. Revista de Estudios Históricos es parte de Revistas UANL, proyecto de la Dirección de Tecnologías de Información, de la Coordinación de Sistemas para Bibliotecas, de la Subdirección de Sistemas Académicos. Teléfono: 818329-4105. Correo electrónico: revistas@uanl.mx.

Foto de portada: D.R. (C) Fototeca Nuevo León-CONARTE, Fondo: Fausto Tovar.

Centro de Estudios Humanísticos. Biblioteca Universitaria Raúl Rangel Frías, Av. Alfonso Reyes No. 4000 Nte. Col. Regina, C.P. 64290, Monterrey, Nuevo León, México. Teléfono: 8183294000 ext. $6533 . \quad$ Correo electrónico: historia.ceh@uanl.mx Sitio web: https://sillares.uanl.mx/index.php/s.

Derechos reservados. Se permite la reproducción parcial para fines académicos citando la fuente.

Impreso en Monterrey, Nuevo León, México. 


\title{
Sillares
}

Revista de Estudios Históricos

sillares.uanl.mx

\section{Fotografía, ciudad y sillares: el centro de Monterrey en la lente de Fausto Tovar Martínez.}

\author{
Jaime Sánchez-Macedo \\ El Colegio de Michoacán \\ orcid.org//0000-0001-6231-7204
}

Copyright: () 2021, Sánchez-Macedo Jaime. This is an openaccess article distributed under the terms of Creative Commons Attribution License [CC BY 4.0], which permits unrestricted use, distribution, and reproduction in any medium, provided the original author and source are credited.

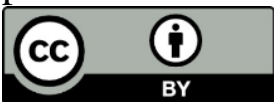

DOI: https://doi.org/10.29105/sillares1.1-7 


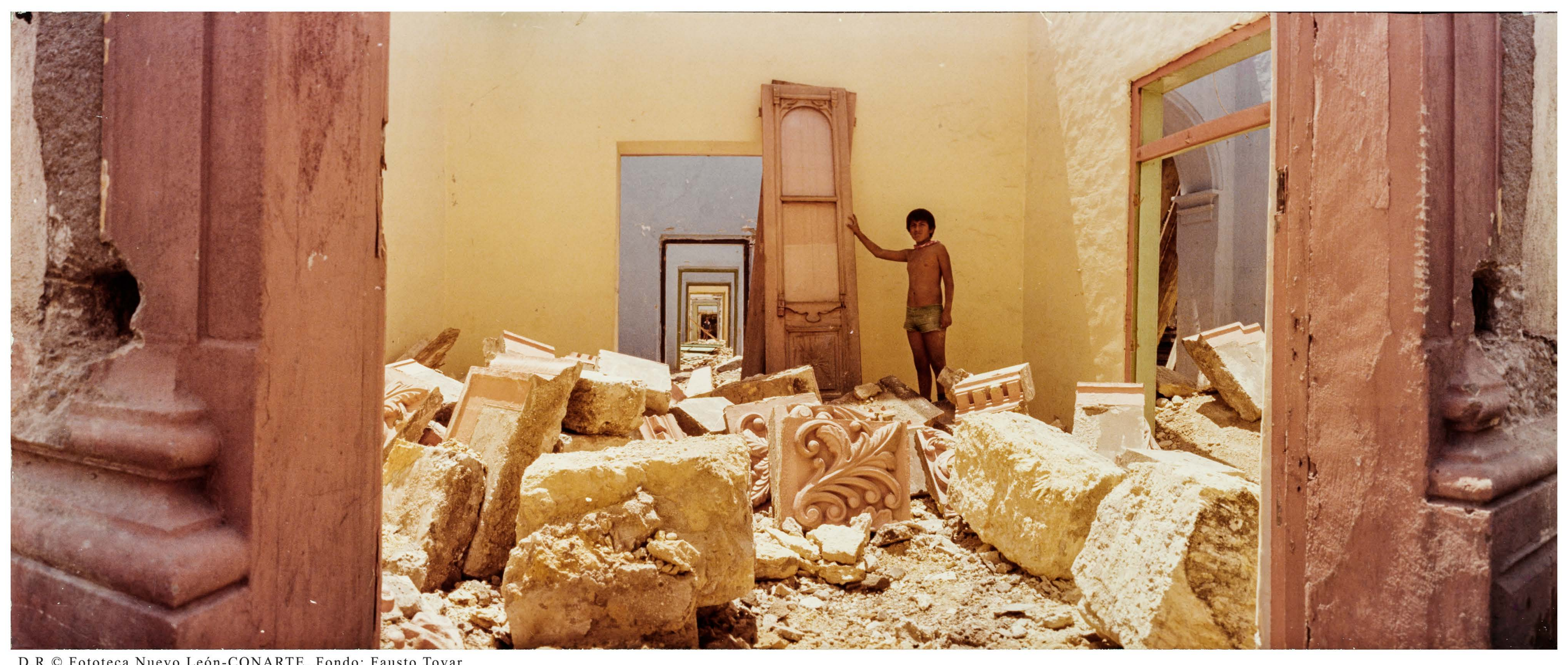




\section{Fotografía, ciudad y sillares: el centro de Monterrey en la lente de Fausto Tovar Martínez ${ }^{1}$}

Jaime Sánchez-Macedo

El Colegio de Michoacán

orcid.org/0000-0001-6231-7204

Para inaugurar esta sección de la revista Sillares se eligió comenzar por la reseña de un documento fotográfico doblemente pertinente. Por un lado, se trata de una toma con el aura particular que identifica las fotografías del centro de Monterrey, capital del estado de Nuevo León en México, antes de la edificación del megaproyecto de espacio público conocido popularmente como Macroplaza. $^{2}$ Al mismo tiempo, esta fotografía

\footnotetext{
${ }^{1}$ El presente artículo se elaboró a partir de la investigación realizada para el texto Donde habita el olvido. Conformación y desarrollo del espacio público en el primer cuadro de la ciudad de Monterrey, 1980-2007, publicado por el Consejo para la Cultura y las Artes en 2019. Se agradece el apoyo brindado por Roberto Ortiz Giacomán en la reprografía de las fotografías y la realización de entrevistas con los hijos de Fausto Tovar.

${ }^{2}$ Oficialmente, el nombre del proyecto es Gran Plaza, aunque prácticamente desde su inauguración fue nombrada por los medios de comunicación y la población en general como Macroplaza. En su momento el nombre Macroplaza fue rechazado por las autoridades gubernamentales y ciertos grupos intelectuales debido al barbarismo resultante de la conjunción de un prefijo griego "macro" con una palabra de origen latino "plaza". Actualmente es común referirse a este espacio público simplemente como La macro. Véase José Emilio Amores, "Monterrey: una cultura propia", en Nuevo León en el siglo XX. La industrialización. Del segundo auge industrial a la crisis de 1982, coord. Isabel Ortega Ridaura (Monterrey: Fondo Editorial Nuevo León, 2007), 101.
}

Sillares, vol. 1, núm. 1, 2021

DOI: https://doi.org/10.29105/sillares1.1-7 
constituye un de los documentos fehacientes acerca de la destrucción de inmuebles de sillar que lamentablemente ha devenido en una práctica común desde hace tiempo, siendo este uno de los elementos más importantes de la arquitectura vernácula del noreste mexicano. Por si fuera poco, de entre los cientos de edificios que fueron arrasados para dar paso a la Gran Plaza, el que aparece parcialmente demolido en la imagen fotográfica no era uno cualquiera. Se trata de un edificio que bien podría haberse considerado parte del patrimonio urbano de Monterrey, no sólo por su temporalidad y sus características arquitectónicas, sino por quien fuera su huésped a finales del siglo XIX.

La historia de la fotografía que nos atañe comienza hacia 1980, cuando el gobernador en turno Alfonso Martínez Domínguez (1979-1985) impuso para la ciudad uno de los procesos de transformación urbana de mayor relevancia en el país, proyectando la erección de una enorme plaza sobre las seis manzanas que separaban el edificio de gobierno municipal de Monterrey con respecto a la sede del ejecutivo estatal. Este proyecto fue enarbolado no solo por la construcción del espacio público, sino también -y más importante aún- porque a partir de dicha plaza se conformaría un distrito financiero que serviría como sede para los corporativos de la burguesía local y para los 
nuevos inversores que arribaran a la urbe regiomontana. Abiertamente se dijo que el propósito era sustituir "lo viejo y decadente", 3 que era como los agentes privados y del gobierno que gestionaron el proyecto concebían el centro de Monterrey. En total, la Gran Plaza -el espacio público y el área reservada para el distrito de negocios- abarcó 40 hectáreas, lo que significó la tabla rasa de la mayor parte del casco antiguo, la traza histórica, los comercios, barrios centrales, un manantial, un río y tres puentes históricos, además de la aniquilación de un sinfín de prácticas y representaciones asociadas con el habitar de esa porción neurálgica de la ciudad.

Fue en este contexto que el fotógrafo Fausto Tovar Martínez decidió asirse con su cámara para registrar el estado de las calles del centro de Monterrey, antes, durante y después de la construcción de la Gran Plaza. ${ }^{4}$ Tovar Martínez legó así un

\footnotetext{
${ }^{3}$ Archivo General del Estado de Nuevo León (AGENL), La Gran Plaza. La nueva cara de Monterrey, 1984, 8-13.

${ }^{4}$ Es importante aclarar que a la fecha se desconoce el número exacto de las fotografías sobre el centro de Monterrey realizadas por Fausto Tovar. En la Fototeca Nuevo León fue posible localizar sólo 31 impresiones en opaco de gran formato, todas a color, sin que se haya logrado consultar el resto del fondo documental que contiene, además de impresiones, negativos y otros procesos fotográficos. Por su parte, el usuario de Facebook identificado como Hernán Bastian colgó al grupo virtual Monterrey viaje al pasado un total de 39 fotografías atribuidas a Fausto Tovar, entre las que incluyó las mismas tomas
}

Sillares, vol. 1, núm. 1, 2021

DOI: https://doi.org/10.29105/sillares1.1-7 
conjunto de al menos 38 documentos imagéticos ${ }^{5}$ que podemos contrastar con el discurso difundido por los promotores del proyecto, ya que permiten conocer el estado previo a la devastación como ningún otro registro visual de la época.

Por lo común, cuando es referido aquello que se echó abajo por la Gran Plaza se suelen utilizar fotografías de épocas anteriores que no corresponden con la imagen de la ciudad a finales de la década de los setenta, ${ }^{6}$ ya que al parecer no hubo un esfuerzo institucional por crear y/o conservar un registro pormenorizado de las calles y edificios que finalmente fueron

resguardadas en la Fototeca del estado. A estas habría que sumar la serie sobre el Cine Elizondo reproducida en el libro Monterrey en 400 fotografías publicado por el Museo de Arte Contemporáneo (Marco) en 1996.

${ }^{5}$ Siguiendo a Roca y Aguayo, se utiliza la locución portuguesa imagético para referir a la generalidad de documentos que, entre sus múltiples especificidades, tienen la de ser portadores de una imagen. En ese sentido, se considera que la fotografía es un soporte documental no sólo por la imagen que contiene, sino también por el soporte -o soportes- que la integra. Fernando Aguayo y Lourdes Roca, coord., Investigación con imágenes. Usos y retos metodológicos (México: Instituto Mora, 2012), 8.

${ }^{6}$ Muestra de ello son los trabajos de Casas y Prieto, en cuyos textos refieren ampliamente a la Gran Plaza aunque la mayor parte del corpus de imágenes que utilizan en su análisis son de una temporalidad anterior y más bien alejada a la del proyecto. Véase Juan Manuel García Casas, Imaginarios interrumpidos. Ensayo sobre el patrimonio perdido de Monterrey (Monterrey: Conarte, 2015); José Manuel Prieto González, Patrimonio moderno y cultura arquitectónica en Monterrey: claves de un desencuentro (Monterrey: Fondo Editorial Nuevo León, 2014).

Sillares, vol. 1, núm. 1, 2021

DOI: https://doi.org/10.29105/sillares1.1-7 
demolidos, más allá de iniciativas personales como la de Fausto Tovar. Aunado a ello, el acervo completo de este fotógrafo local se desconoce debido a que permanece en su gran mayoría sin ser procesado como parte de los fondos históricos de la Fototeca del estado de Nuevo León. ${ }^{7}$ Por otro lado, la fotografía como la que aquí se reseña cobra una relevancia mayúscula toda vez que al día de hoy no se ha encontrado rastro alguno de la documentación asociada con la realización de la Gran Plaza más allá de los decretos legislativos, notas periodísticas de la época, unos pocos planos y una publicación para difundir el proyecto una vez concluido. Las fotografías de Fausto Tovar constituyen así una fuente primaria fundamental para estudiar el cambio de imagen del centro de Monterrey, así como la transformación de los modos de habitar el espacio urbano.

Antes de hablar del contenido de la fotografía de Fausto Tovar, se retomarán algunos datos biográficos de su autor y de la naturaleza del proyecto de la Gran Plaza, esto como parte de una metodología de investigación social con imágenes centrada en

\footnotetext{
${ }^{7}$ La fotografía que aquí se reseña en conjunto con otras piezas de la misma serie fueron obtenidas en su versión digital gracias al invaluable apoyo de Roberto Ortiz Giacomán, quien realizó la reprografía de las impresiones de gran formato que resguarda la Fototeca Nuevo León.
}

Sillares, vol. 1, núm. 1, 2021

DOI: https://doi.org/10.29105/sillares1.1-7 
profundizar acerca del contexto de producción de este tipo de fuentes primarias. ${ }^{8}$ Es importante subrayar que el empleo de imágenes -fijas o en movimiento- en la investigación en ciencias sociales requiere del acopio de elementos que permitan comprender de dónde y cómo surgen estos documentos imagéticos, ya que no necesariamente y por sí misma "una imagen dice más que mil palabras".

A la fecha se ha recuperado poca información biográfica de Fausto Tovar Martínez, ${ }^{9}$ quien nació en San Luis Potosí el 15 de septiembre de 1926. Por lo que se ha podido constatar, en su ciudad natal, previo al oficio de fotógrafo, Fausto Tovar se

\footnotetext{
${ }^{8}$ Lourdes Roca et al., Tejedores de imágenes. Propuestas metodológicas de investigación y gestión del patrimonio fotográfico y audiovisual (México: Instituto Mora, LAIS, Conacyt, 2014), 108.

${ }^{9}$ Existe una semblanza biográfica de Fausto Tovar en el volumen Monterrey en 400 fotografías, así como una emisión del programa Entre historias conducido por Elvira Ramos del canal de internet Regioenvivo.Tv en la cual participa Marta Tovar, hija de Fausto Tovar. Recientemente el mismo Roberto Ortiz Giacomán ha llevado a cabo una serie de entrevistas con por lo menos tres de los hijos de Fausto Tovar: Imelda, Julio y Fausto. Parte de la información de estas entrevistas es referida a lo largo del texto con la autorización de Ortiz Giacomán. Véase también Ricardo Elizondo, José Antonio Rodríguez y Xavier Moyssén, Monterrey en 400 fotografías (Monterrey: Museo de Arte Contemporáneo, 1996); programa Entre historias en Regioenvivo.Tv, 23 de enero de 2020, disponible en $<$ https://www.facebook.com/RegioEnVivo.TV/videos/188087359258906> [última consulta enero 2021].
}

Sillares, vol. 1, núm. 1, 2021

DOI: https://doi.org/10.29105/sillares1.1-7 
convirtió en aprendiz del pintor Felipe Moreno, quien lo instruyó en la realización de paisajes y retratos, así como en el retoque de las pinturas de las iglesias de la localidad. ${ }^{10}$ Ya con una instrucción en la pintura al óleo, cerca de los veinte años de edad, entre 1945 y 1946, migró a Monterrey para alcanzar a su madre que unos años antes se había mudado a esta ciudad.

Para mediados del siglo $\mathrm{XX}$, la urbe regiomontana contaba ya con una sólida tradición fotográfica con grandes hitos como Desiderio Lagrange, Jesús R. Sandoval, Refugio Z. García, Eugenio Espino Barros y Alberto Flores Varela, entre otros, ${ }^{11}$ gracias a la existencia de una gran demanda de fotografías alimentada en parte por el desarrollo industrial del estado de Nuevo León. Aunque antes que en la fotografía, Tovar Martínez trabajó en un taller de anuncios luminosos llamado "Rótulos eléctricos", recién llegado a Monterrey tuvo contacto con algunos de los fotógrafos locales gracias a que su medio hermano era

${ }^{10}$ María del Pilar Pérez Cruz, "La obra del pintor Felipe Moreno Díaz, en la ciudad de San Luis Potosí: 1950-1970" (tesina de especialidad, Universidad Autónoma de San Luis Potosí, 2002), 25.

${ }^{11}$ Véase Roberto Ortiz Giacomán, "Unión, arte y progreso", Alquimia. Revista del Sistema Nacional de Fototecas 18, núm. 54 (mayo-agosto 2015): 52-58; José Antonio Rodríguez, "Testimonio de la fotografía", en Elizondo, Rodríguez y Moyssén, coord., Monterrey en 400 fotografías.

Sillares, vol. 1, núm. 1, 2021

DOI: https://doi.org/10.29105/sillares1.1-7 
asistente en el estudio Foto Selecta de Alberto Flores Varela y a que la familia Espino Barros era cliente del negocio de anuncios luminosos. Con estos últimos entablaría una relación de admiración y amistad una vez en el oficio fotográfico. ${ }^{12}$

Es lógico suponer que, derivado de la competencia profesional entre el gremio de fotógrafos establecidos en Nuevo León, cada uno buscara destacarse de entre los demás por algún medio. En ese sentido, el catálogo ofertado por Fausto Tovar desde su estudio-taller, ubicado en la calle Agustín Melgar de la colonia Terminal, ${ }^{13}$ sobresalía por al menos tres servicios: la fotografía publicitaria de productos, las impresiones fotográficas de gran formato, también conocidos como fotomurales, y las fotografías aéreas oblicuas. ${ }^{14}$ Fue precisamente la fotografía aérea lo que vinculó a Tovar Martínez con el proyecto de la Gran Plaza.

\footnotetext{
${ }^{12}$ Entrevista con la familia Tovar realizada por Roberto Ortiz Giacomán, enero de 2020.

${ }^{13}$ Antes de 1970 Fausto Tovar tuvo su estudio en la calle 5 de mayo núm. 830, el cual compartía con Cástulo Medina. Entrevista con la familia Tovar realizada por Roberto Ortiz Giacomán, enero de 2020.

${ }^{14}$ Sobre la dinámica del taller-estudio de Fausto Tovar sabemos que en su administración se involucraba toda la familia Tovar, sus cinco hijos y su esposa. Entrevista con la familia Tovar realizada por Roberto Ortiz Giacomán, enero de 2020.
}

Sillares, vol. 1, núm. 1, 2021

DOI: https://doi.org/10.29105/sillares1.1-7 
La decena de tomos que componen la colección de notas periodísticas acerca del desarrollo de la Gran Plaza resguardados en el Archivo Histórico de Monterrey (AHM) ${ }^{15}$ dan cuenta del sigilo y la rapidez con la cual se inició el proyecto, fenómeno que se replica también en otras partes del mundo con iniciativas de intervención urbana de gran escala. ${ }^{16}$ Mientras que, por un lado, la población más directamente afectada por los trabajos de demolición se quejó constantemente por la falta de información oficial, ${ }^{17}$ por otro, el decreto oficial aprobatorio de la Gran Plaza por parte del poder legislativo no se dio sino hasta finales de $1981,{ }^{18}$ cuando el proyecto llevaba ya un considerable avance en los trabajos de demolición. Por lo tanto, no es un aspecto menor el que la notificación a Fausto Tovar sobre la inminente realización de la Gran Plaza le permitiera realizar un registro con

\footnotetext{
${ }^{15}$ Nos referimos al fondo documental clasificado como Colección Libros Gran Plaza que compilan el seguimiento mediático al desarrollo del proyecto.

${ }^{16}$ Marshall Berman, Todo lo sólido se desvanece en el aire. La experiencia de la modernidad (México: Siglo XXI Editores, 1989), 307-308.

${ }^{17}$ Archivo Histórico de Monterrey (AHM), Colección Libros Gran Plaza, t. II, p. 104, María Belmonte, "Dudas, desalojos y demoliciones", en Tribuna Diario, 23 de octubre de 1981.

${ }^{18}$ Congreso del estado de Nuevo León, expediente núm. 199, decreto núm. 156, 25 de noviembre de 1981. Documento obtenido mediante solicitud a la unidad de transparencia del Congreso de Nuevo León.
}

Sillares, vol. 1, núm. 1, 2021

DOI: https://doi.org/10.29105/sillares1.1-7 
la anticipación suficiente para documentar el centro todavía inalterado por los buldóceres.

Ángela Alessio Robles, primera directora del órgano ejecutor del proyecto (Prourbe), comisionó a Tovar Martínez la realización de una serie de fotografías aéreas del terreno donde se erigiría la Gran Plaza. ${ }^{19} \mathrm{Al}$ respecto, existen importantes diferencias entre la realización de un registro fotográfico aéreo y uno a nivel de calle, ya que, si bien ambos pueden documentar la misma porción del espacio urbano, el grado de detalle y los aspectos que cada uno nos permite visualizar resultan sumamente distintos. De inicio, las tomas aéreas dan una visión general del espacio y posibilitan una rápida identificación de sus principales elementos constitutivos, en especial los edificios de mayores dimensiones, vialidades y la traza urbana. Es por ello que, como en el caso que ahora nos ocupa, antes que existieran las imágenes satelitales, la fotografía aérea se utilizó recurrentemente en la planeación urbana; una de las tomas aéreas de Fausto Tovar, por ejemplo, sirvió para hacer un fotomontaje de los edificios que supuestamente se construirían en el centro de Monterrey como

${ }^{19}$ Entrevista con la familia Tovar realizada por Roberto Ortiz Giacomán, enero de 2020.

Sillares, vol. 1, núm. 1, 2021

DOI: https://doi.org/10.29105/sillares1.1-7 
parte del distrito financiero. ${ }^{20}$ Por su parte, en los estudios históricos la comparación entre distintas fotografías aéreas permite observar el conjunto de elementos urbanos que han permanecido o que se han transformado con el paso del tiempo. ${ }^{21}$

En cambio, la fotografía a nivel de calle transmite una experiencia visual más cercana a la del transeúnte, brinda también una mejor idea de las dimensiones de los inmuebles con respecto a la escala humana y, finalmente, muestra con detalle los elementos arquitectónicos de cada edificio. Es probable que tales diferencias entre las tomas aéreas y a nivel de calle llevaran a Fausto Tovar a realizar un registro fotográfico propio, que documentara con mayor finura la transformación del centro de Monterrey más allá de la exigencia de las autoridades gestoras de la Gran Plaza. En ese sentido, el escueto registro fotográfico a nivel de calle utilizado por el gobierno para sustentar el discurso de decadencia del centro de Monterrey se incluyó en dos publicaciones realizadas para enaltecer la administración de

\footnotetext{
${ }^{20}$ El negativo de este fotomontaje con la superposición de los edificios sobre la toma aérea oblicua forma parte del Fondo Fausto Tovar de la Fototeca Nuevo León, sin embargo, se trata de una pieza aún sin catalogar.

${ }^{21}$ Roca, "La fotografía aérea en México para el estudio de la ciudad: el crucero de El Caballito", Anais do Museu Paulista: História e Cultura Material 19, núm. 2 (diciembre de 2011): 73-82.
}

Sillares, vol. 1, núm. 1, 2021

DOI: https://doi.org/10.29105/sillares1.1-7 
Martínez Domínguez: se trató de la revistilla La nueva cara de Monterrey, así como del libro firmado por Mario Santoscoy Monterrey. Área metropolitana. Ambos contienen la misma serie de tomas a nivel de calle del centro de Monterrey, ${ }^{22}$ así como dos fotografías aéreas del estado previo y posterior realizadas por el propio Fausto Tovar.

La comparación entre las fotografías de las calles de Monterrey difundidas por el gobierno con respecto a las de Tovar Martínez muestra importantes diferencias. En las primeras se destacan dos aspectos que los agentes urbanos detrás de la Gran Plaza repitieron una y otra vez como justificación del proyecto: la estrechez de las calles y el giro comercial de una parte de los negocios asentados en el centro de la ciudad. Para ello se utilizaron encuadres cerrados que en primer plano muestran vehículos ocupando la mayor parte de la composición. Asimismo, para reforzar el sentido de las imágenes, éstas se acompañaron

\footnotetext{
${ }^{22}$ Si bien el texto La nueva cara de Monterrey no incluyó el crédito fotográfico de ninguna de las numerosas imágenes que aparecen en la publicación, en Monterrey. Área metropolitana se menciona que el conjunto de fotografías de aquel volumen fueron realizadas por Camilo Garza y Garza, Eduardo D'Regules, Xossé de Sade y Miguel Vera bajo la dirección de Mario Casasola. No obstante, por lo menos la toma aérea que se incluye en ambos fue realizada por Fausto Tovar. AGENL, Monterrey. Área metropolitana, 1984.
}

Sillares, vol. 1, núm. 1, 2021

DOI: https://doi.org/10.29105/sillares1.1-7 
con pies de foto como el siguiente: "Asfixiado por manzanas de edificaciones viejas y decadentes, el centro de la ciudad se había convertido en una de las zonas más deprimidas y rezagadas de la metrópoli, donde predominaban los edificios decadentes como comercios, viviendas y talleres". ${ }^{23}$ Empero, las fotografías difundidas por el gobierno pudieran no corresponder estrictamente con el momento previo a los trabajos de demolición para la Gran Plaza, ya que en por lo menos una de las tomas se aprecia claramente una pancarta con la leyenda "Prourbe. Monterrey se moderniza" cubriendo la entrada de un inmueble aparentemente desocupado, lo cual indica que ya había dado inicio el proyecto. ${ }^{24}$

En tanto, Fausto Tovar prácticamente realizó una labor opuesta utilizando un lente gran angular y posicionándose en muchas de las bocacalles que serían afectadas por el proyecto. Así, logró captar las arterias del centro con una amplitud que está lejos de apreciarse en las tomas realizadas por el gobierno. De entre los aspectos a destacar del conjunto de fotografías hechas por Fausto Tovar está la diversidad de negocios que aparecen en

${ }^{23}$ AGENL, La Gran Plaza. La nueva cara de Monterrey, 1984, 9.

${ }^{24}$ AGENL, La Gran Plaza. La nueva cara de Monterrey, 1984, 9.

Sillares, vol. 1, núm. 1, 2021

DOI: https://doi.org/10.29105/sillares1.1-7 
su registro, y no solamente las cantinas y los talleres de reparación automotriz que fueron denostados en la propaganda para la Gran Plaza. Tovar Martínez fotografió además el interior de una vecindad anteriormente ubicada en la manzana de las calles 15 de Mayo y Escobedo, así como una de las entradas al río Santa Lucía convertido en desagüe desde el siglo XIX. Otra característica de las fotografías del estado previo a la Gran Plaza consiste en que se trató de una serie que no se realizó en un único día. Así lo muestran dos tomas de la esquina de las calles Ignacio Zaragoza y Juan Ignacio Ramón: una en la que se observa el cruce con poca afluencia peatonal, y otra que se realizó en el transcurso de un populoso desfile; la segunda deja ver además los primeros avances de las demoliciones por la desaparición de una sección del edificio que albergaba el restaurante-bar "Fornos", la cual sí aparece en la toma sin el desfile. Todo lo cual nos da indicio de un registro del centro de Monterrey sistemático y bien pensado.

De entre los referentes urbanos retratados por Fausto Tovar, sin duda el más conocido es el Cine Elizondo, inmueble dedicado al séptimo arte que se caracterizó por su profusa decoración de inspiración asiática. Este edificio fue sin duda el que mayor polémica causó cuando se determinó su 
derrumbamiento, siendo defendido por una parte de la población con motivo de sus peculiares elementos arquitectónicos. ${ }^{25}$ No obstante, en la erección de la Gran Plaza, el Cine Elizondo sólo adquirió valor histórico por ser uno de los primeros edificios demolidos en Monterrey con dinamita y porque además esta acción fue llevada a cabo por una de las primeras mujeres egresadas de la carrera de ingeniería de la Universidad Autónoma de Nuevo León (UANL), Leticia Ruvalcaba. ${ }^{26}$

Otro sitio sacrificado por el proyecto fue la Fuente de Monterrey, un espacio público ubicado en el cruce de las calles Allende e Ignacio Zaragoza. La fuente tenía de fondo decorativo el mural Fundación de Monterrey, obra del arquitecto y ex rector de la universidad, Joaquín A. Mora, siendo este uno de los pocos elementos que se conservó tras la construcción de la Gran Plaza y que fue recolocado en un sitio cercano a su ubicación original. Desde antes de la construcción de la Fuente de Monterrey,

${ }^{25}$ AHM, Colección Libros Gran Plaza, t. I, p. 99, Ricardo Espinosa Cárdenas, "Demolerán el Cine Elizondo", El Norte, 20 de junio de 1981; Prieto, Patrimonio moderno y cultura arquitectónica en Monterrey: claves de un desencuentro, 80.

${ }^{26}$ Daniel de la Fuente, "La demoledora", en Perfiles e historia, El Norte, 6 de febrero de 2005.

Sillares, vol. 1, núm. 1, 2021

DOI: https://doi.org/10.29105/sillares1.1-7 
históricamente este cruce de calles se había caracterizado por la presencia del vital líquido, ya que debajo se localiza uno de los manantiales que existen en el centro de la ciudad. Por tal motivo, antes que existiera la fuente, en el sitio se localizó durante algún tiempo la Alberca Monterrey, una piscina natural de uso público bastante popular entre la población durante la primera mitad del siglo XX. ${ }^{27}$

Finalmente, la fotografía de Fausto Tovar motivo de la presente reflexión, documenta un tercer referente urbano devastado por causa de la Gran Plaza; se trata de la casa del connotado médico e historiador José Eleuterio González, conocido en Monterrey como "Gonzalitos". ${ }^{28}$ La importancia del inmueble localizado sobre la calle Dr. Coss, entre Matamoros y Padre Mier, consistía en que precisamente ahí murió el galeno el día 4 de abril de 1888. Como sucedió con el resto del centro de Monterrey y los demás referentes urbanos echados abajo por la Gran Plaza, simpatizantes de la transformación urbana

${ }^{27}$ Casas, Imaginarios interrumpidos. Ensayo sobre el patrimonio perdido de Monterrey, 102.

28 Véase Édgar Iván Espinosa Martínez, "La cultura nacional desde las regiones en el siglo XIX. El caso de José Eleuterio González (1813-1888) en Nuevo León”, Nóesis. Revista de Ciencias Sociales y Humanidades 24, núm. 48 (julio-diciembre, 2015): 198-225.

Sillares, vol. 1, núm. 1, 2021

DOI: https://doi.org/10.29105/sillares1.1-7 
comenzaron por denostar el valor histórico de la finca, argumentando en este caso que la casa nunca fue propiedad de Gonzalitos. Por su parte, el cronista oficial de Monterrey, José P. Saldaña, afirmó que la casa no era un edificio que mereciera la conservación, ya que una placa era más que suficiente para rescatar el valor histórico del lugar; de lo contrario, se corría el riesgo de terminar con una "mini plaza" en lugar de una Gran Plaza, según afirmó el mismo cronista ante la prensa. Cabe mencionar que poco tiempo antes el alcalde de Monterrey entre 1980 y 1982, Pedro Quintanilla, había prometido en campaña hacer un museo de la medicina en aquel sitio que ahora quedaba destinado a la picota. ${ }^{29}$ Aunado a todo esto, la responsable de la ejecución de la Gran Plaza, Ángela Alessio Robles, negó que el proyecto a su cargo fuera el motivo de la demolición del edificio, ya que no se tenía contemplada la demolición de los inmuebles de la acera oriente de la calle Dr. Coss. ${ }^{30}$ Sin embargo, coincidentemente con el arranque de la Gran Plaza la casa se echó abajo, ya fuera por decisión de sus propietarios que aprovecharon

${ }^{29}$ AHM, Colección Libros de la Gran Plaza, t. 1, p. 111, Víctor S. Canales, "Nadie puede parar la demolición de la casa", El Norte, 24 de junio de 1981. ${ }^{30}$ AHM, Colección Libros de la Gran Plaza, t. 1, p. 104, ¡Demuelen Casa de Gonzalitos", El diario de Monterrey, 23 de junio de 1981.

Sillares, vol. 1, núm. 1, 2021

DOI: https://doi.org/10.29105/sillares1.1-7 
que en todo el sector se realizaban trabajos de demolición, o bien, por la acción del gobierno.

La destrucción de la casa de Gonzalitos llamó la atención de Fausto Tovar, por lo menos para la realización de dos tomas del inmueble. La primera de estas retrata la fachada parcialmente demolida y vista desde un punto cercano al cruce de las calles Padre Mier y Dr. Coss. Esta toma nos deja ver además que la casa parece ser el único inmueble en proceso de demolición en todo ese lado de la acera, lo cual podría sustentar los dichos de la ingeniera Alessio Robles.

Llegamos así a la fotografía que es motivo de todo este análisis y que además ilustra la portada de la nueva época de la revista de historia del Centro de Estudios Humanísticos de la UANL. En ella observamos la primera habitación de la casa de Gonzalitos, con el marco de la entrada principal en primer plano; a pesar de la leve deformación de la imagen provocada por el tipo de lente, mediante el primer plano es posible hacerse una idea del grosor de los muros de la fachada. Por el suelo del inmueble que se aprecia en una elevación superior a la de la vía peatonal, que es el punto desde donde apuntó su cámara Fausto Tovar, observamos bloques de sillar, algunos con los elementos 
decorativos del inmueble -ya fueran de yeso o estuco-, los cuales podrían haber correspondido con alguna cornisa o capitel. El más notorio de éstos por su localización al centro de la imagen, lleva un motivo floral de estilo rococó; las decoraciones constituyen un indicio de la calidad constructiva del inmueble, así como de la clase social a la cual estaba destinado. La única figura humana en toda la toma es la de un niño que posa sin camisa, apoyando su mano derecha en una puerta de madera también con detalles decorativos.

De entre todas las fotografías del centro de Monterrey elaboradas por Tovar Martínez que se han podido observar, sólo hay otra en la cual posa también un niño; no obstante, se trata de alguien de menor edad que fue retratado en una parte de la Gran Plaza a punto de ser concluida. En ambos casos, los infantes nos dan una idea clara de las proporciones del espacio con relación a la escala humana. Por último, el plano posterior de la toma muestra la amplitud del inmueble, así como la dimensión de la demolición. El considerable número de habitaciones que se aprecia al fondo -el acercamiento a la imagen digital de la fotografía permite identificar al menos cinco habitaciones-opera como el efecto provocado por la contraposición de espejos, como 
si se tratara de un reflejo infinito de la demolición del centro de Monterrey, delante y detrás del fotógrafo. Las notas periodísticas, producto de la polémica generada por el derrumbe del inmueble, nos dan la certeza del año de las dos tomas de la casa de Gonzalitos, 1981, así como un posible rango de meses, entre mayo y julio.

Al final, el anhelado distrito financiero que acompañaría la Gran Plaza quedó lejos de concretarse por diversos motivos que se han destacado en investigaciones previas, ${ }^{31}$ dejando el terreno de la finca en espera de hallar un uso más lucrativo para sus propietarios. El único criterio de conservación patrimonial si es que se puede llamar así- para el sitio, fue aquel propuesto por José P. Saldaña y que consistió en la colocación de una placa en el lugar que hoy en día funciona como un estacionamiento privado. En tanto, Fausto Tovar utilizó las dos tomas de la casa de Gonzalitos y el resto de las fotografías del centro de Monterrey

\footnotetext{
${ }^{31}$ Jaime Sánchez-Macedo, Donde habita el olvido. Conformación y desarrollo del espacio público en el primer cuadro de la ciudad de Monterrey, 1980-2007 (Monterrey: Conarte, Museo de Historia Mexicana, 2019); Patrice Melé, La producción del patrimonio urbano (México: Ciesas, 2006), 243; Rodrigo Fernando Escamilla Gómez, "De la industria a los servicios, la macroplaza y los primeros indicios de la servicialización de la ciudad de Monterrey (19791986)" (tesis de maestría, Universidad Nacional Autónoma de México, 2014).
}

Sillares, vol. 1, núm. 1, 2021

DOI: https://doi.org/10.29105/sillares1.1-7 
para hacer por lo menos una exposición de su obra. Para este propósito se produjeron las impresiones en opaco de gran formato que hoy en día están en custodia de la Fototeca Nuevo León. Cabe mencionar que a pesar de las óptimas condiciones de resguardo de la institución, la calidad de las impresiones policromáticas ha generado una importante pérdida de color en algunas de las fotografías, situación que se podría agravar en los años venideros.

A manera de conclusión basta decir que para muchos de los habitantes de Monterrey, que además conocen cuál fue el destino final del terreno de la finca, la fotografía del interior de la casa de Gonzalitos posee un punctum en los términos argüidos por Barthes; es decir, se trata de una imagen que por uno o varios de los elementos que contiene la imagen fotográfica "hiere" al observador como una pulsación. ${ }^{32}$ Los sillares derruidos y el niño que posa en la fotografía de Fausto Tovar generan una afección en la sensibilidad de quien mira esta imagen, ya sea por la extraña belleza de la toma, o bien, porque desde hace un par de años los martilleos han vuelto a ser un eco constante por todo el centro de Monterrey. Sin embargo, hoy día la suplantación del patrimonio

${ }^{32}$ Roland Barthes, La cámara lúcida. Nota sobre la fotografía (Barcelona: Paidós, 1989), 58-85.

Sillares, vol. 1, núm. 1, 2021

DOI: https://doi.org/10.29105/sillares1.1-7 
urbano no es por la construcción de espacio público, sino por el flujo de capitales financieros sumados a la especulación inmobiliaria que demanda una nueva tabla rasa en el espacio urbano.

Por otro lado, en una lectura a nivel iconográfico del documento imagético, ${ }^{33}$ la fotografía de Fausto Tovar representa la picota del "progreso" que se yergue sobre el patrimonio urbano de Monterrey. Se vuelve necesario entonces voltear a ver nuevamente las fotografías de Fausto Tovar sobre el centro de la ciudad para reflexionar sobre los costos de las transformaciones urbanas de gran escala. Asimismo, el legado de este fotógrafo invita a tomar nuestras cámaras digitales y registrar todos aquellos edificios de la ciudad que parecen nuevamente a punto de desvanecerse en el aire. De lo contrario, sólo quedarán los discursos de abandono y decadencia que, antes y ahora, han servido de justificación para echar abajo el patrimonio urbano.

33 Roca et. al., Tejedores de imágenes. Propuestas metodológicas de investigación y gestión del patrimonio fotográfico y audiovisual, 100-106.

Sillares, vol. 1, núm. 1, 2021

DOI: https://doi.org/10.29105/sillares1.1-7 


\section{Referencias}

\section{Archivo}

Archivo General del Estado de Nuevo León

Archivo Histórico de Monterrey

\section{Bibliografía}

Aguayo, Fernando y Lourdes Roca coord. Investigación con imágenes. Usos y retos metodológicos. México: Instituto Mora, 2012.

Amores, José Emilio, "Monterrey: una cultura propia", en Nuevo León en el siglo XX. La industrialización. Del segundo auge industrial a la crisis de 1982, coord. por Isabel Ortega Ridaura, 73-108. Monterrey: Fondo Editorial Nuevo León, 2007.

Barthes, Roland. La cámara lúcida. Nota sobre la fotografía. Trad. por Joaquim Sala Sanahuja. Barcelona: Paidós, 1989.

Berman, Marshall, Todo lo sólido se desvanece en el aire. La experiencia de la modernidad. Trad. por Andrea Morales Vidal. México: Siglo XXI Editores, 1989.

Casas García, Juan Manuel. Imaginarios interrumpidos. Ensayo sobre el patrimonio perdido de Monterrey. Monterrey: Conarte, 2015.

Elizondo, Ricardo, José Antonio Rodríguez y Xavier Moyssén. Monterrey en 400 fotografías. Monterrey: Museo de Arte Contemporáneo, 1996. 
Escamilla Gómez, Rodrigo Fernando. "De la industria a los servicios: la macroplaza y los primeros indicios de la servicialización de la ciudad de Monterrey (1979-1986)". Tesis de maestría. Universidad Nacional Autónoma de México, 2014. http://132.248.9.195/ptd2014/septiembre/0718658/Index.html

Espinosa Martínez, Édgar Iván. "La cultura nacional desde las regiones en el siglo XIX. El caso de José Eleuterio González (1813-1888) en Nuevo León". Nóesis. Revista de Ciencias Sociales y Humanidades 24, núm. 48, (juliodiciembre, 2015): 198-225.

Melé, Patrice. La producción del patrimonio urbano. México: Ciesas, 2006.

Ortiz Giacomán, Roberto. "Unión, arte y progreso". Alquimia. Revista del Sistema Nacional de Fototecas 18, núm. 54 (mayo-agosto 2015): 52-58.

Pérez Cruz, María del Pilar. "La obra del pintor Felipe Moreno Díaz, en la ciudad de San Luis Potosí: 1950-1970". Tesis de especialidad. Universidad Autónoma de San Luis Potosí, 2002.

Prieto González, José Manuel, Patrimonio moderno y cultura arquitectónica en Monterrey: claves de un desencuentro. Monterrey: Fondo Editorial Nuevo León, 2014.

Roca, Lourdes, Felipe Morales Leal, Carlos Hernández Marines y Andrew Green [conformados en el Laboratorio Audiovisual de Investigación Social]. Tejedores de imágenes. Propuestas metodológicas de investigación y gestión del patrimonio fotográfico y audiovisual. México: Instituto Mora, Lais, Conacyt, Conaculta, 2014. 
Rodríguez, José Antonio. "Testimonio de la fotografía en Monterrey". En Monterrey en 400 fotografías, Ricardo Elizondo, José Antonio Rodríguez y Xavier Moyssén. Monterrey: Museo de Arte Contemporáneo, 1996.

Sánchez-Macedo, Jaime. Donde habita el olvido. Conformación y desarrollo del espacio público en el primer cuadro de la ciudad de Monterrey, 1980-2007. Monterrey: Conarte, Museo de Historia Mexicana, 2019. 